\section{Factor structure and construct validity of the Generalized Anxiety Disorder 7-item (GAD-7) among Portuguese college students}

\author{
Estrutura fatorial e validade de construto da \\ escala Generalized Anxiety Disorder 7-item (GAD-7) \\ entre alunos universitários em Portugal
}

\section{La estructura del factor y la validez de constructo del Generalized Anxiety Disorder 7-item (GAD-7) \\ entre los estudiantes universitarios en Portugal}

Ana Bártolo 1,2

Sara Monteiro 1

Anabela Pereira 1,3

\begin{abstract}
The Generalized Anxiety Disorder 7-item (GAD-7) scale has been presented as a reliable and valid measure to assess generalized anxiety symptoms in several clinical settings and among the general population. However, some researches did not support the original one-dimensional structure of the $G A D-7$ tool. Our main aim was to examine the factor structure of GAD-7 comparing the one-factor model fit with a two-factor model (3 somatic nature symptoms and 4 cognitive-emotional nature symptoms) in a sample of college students. This validation study with data collected cross-sectionally included 1,031 Portuguese college students attending courses in the six schools of the Polytechnic Institute of Coimbra, Coimbra, Portugal. Measures included the GAD-7, Hospital Anxiety and Depression Scale (HADS) and the University Student Risk Behaviors Questionnaire. Confirmatory factor analysis (CFA) procedures confirmed that neither factor structure was well fitting. Thus, a modified single factor model allowing the error terms of items associated with relaxing difficulties and irritability to covary was an appropriate solution. Additionally, this factor structure revealed configural and metric invariance across gender. A good convergent validity was found by correlating global anxiety and depression. However, this measure showed a weak association with consumption behaviors. Our results are relevant to clinical practice, since the comprehensive approach to GAD-7 contributes to knowing generalized anxiety symptoms trajectory and their correlates within the university setting.
\end{abstract}

Anxiety; Students; Surveys and Questionnaires

\author{
Correspondence \\ A. Bártolo \\ Departamento de Educação e Psicologia, Universidade de Aveiro. \\ Campus Universitário de Santiago, Aveiro 3810-193, Portugal. \\ anabartolo@ua.pt

\footnotetext{
1 Departamento de Educação e Psicologia, Universidade de Aveiro, Aveiro, Portugal.

2 Centro de Investigação em Tecnologias e Serviços de Saúde,

3 Centro de Investigação em Didática e Tecnologia na Formação
} \\ Universidade de Aveiro, Aveiro, Portugal. \\ de Formadores, Universidade de Aveiro, Aveiro, Portugal.
}




\section{Introduction}

Mental illness in college students is a significant public health problem, but only a small minority of students have received adequate and timely treatment ${ }^{1}$. Entering college represents a demanding transition to adulthood 2 and in some cases mental health problems have pre-matriculation onsets 1 .

More specifically, anxiety disorders during college years have been associated with tobacco use and sleep problems ${ }^{3}$ or even low academic performance ${ }^{4}$. Generalized anxiety disorder seems to be one of the most frequent diagnoses 5,6 and its chronic course 7 and negative impact on quality of life is recognized ${ }^{8}$. Some studies using epidemiologic samples indicate that this specific disorder and alcohol or drug use co-occur and are associated 9,10. According to the research by Conway et al. 9, drug use appears as a way of auto-medicating generalized anxiety disorder symptoms. Thus, early detection of generalized anxiety disorder becomes critical, depending on the administration of appropriate and reliable measures.

The Generalized Anxiety Disorders 7-item (GAD-7) scale, originally validated for primary care 11, came to fill a gap in the evaluation of generalized anxiety disorder and replace other measures, e.g., the Hospital Anxiety and Depression Scale (HADS) by Zigmond \& Snaith 12 and the State-Trait Anxiety Inventory-Y (STAI-Y) by Spielberger et al. 13 that assessed global anxiety symptoms without an objective quantification of generalized anxiety disorder symptoms. As a short and objective self-report measure showing strong properties as a screening tool 11 , researchers have tested its psychometric characteristics in several settings. In this context, over the last decade, GAD-7 has been presented as a reliable and valid questionnaire in different languages 14,15,16,17,18 including Portuguese 19, with heterogeneous psychiatric samples 20,21 for specific medical conditions $22,23,24,25$ in the general population 26 and in geriatric samples 27 . However, the one-dimensional nature of GAD-7 proposed by the original model is not consistent in the literature. A good fit of the one-factor structure has not been confirmed in psychiatric samples 20,21 or tested in non-clinical communities of college students, limiting the administration of GAD-7 as an alternative measure to detect generalized anxiety disorder in an academic setting.

Factor structure is a strong indicator of validity, contributing to defining which issues should be considered in evaluating a construct. Given that generalized anxiety disorder is accompanied by symptoms of an autonomic/physical and cognitive nature 28, included as diagnostic criteria for GAD-7, an one-dimensional approach to the construct may have implications for screening, even in community samples. The assessment of generalized anxiety disorder is difficult due to the overlaying of somatic symptoms in anxiety disorders, such as irritability and agitation 29. The GAD-7 tool has even shown sensitivity to other disorders, such as panic disorder, social phobia and post traumatic stress disorder 30 . Accordingly, an independent assessment of items of a somatic/physical and cognitive-emotional nature related to the experience of generalized anxiety disorder may be a solution for the identification and proper treatment of this problem in the university.

Based on the findings of Kertz et al. 21, our main aim was to develop confirmatory factor analysis (CFA) to compare the original one-factor model fit with a model of two latent factors. These authors examined the factorial validity of GAD-7 using CFA procedures and demonstrated the hypothesized one-dimensional model did not fit to the data in a psychiatric sample. Therefore, the model was respecified allowing the error terms of items 4 ("trouble relaxing"), 5 ("being so restless that it is hard to sit still") and 6 ("becoming easily annoyed or irritable") to covary. With this procedure, the model provided a better fit, showing, as suggested by the authors, that the items presented a shared unique variance that could reflect a somatic tension/autonomic arousal factor 21. Beard \& Björgvinsson 20 later confirmed the failure of the one-factor structure. In their research, a better fit was found for a multidimensional factor structure considering items 4,5 and 6 as indicators of an independent factor. Thus, in line with the findings of these two studies, we considered this model of two latent factors with three somatic items (trouble relaxing, agitation and irritability) and four cognitive-emotional items. Moreover, we went beyond other studies by evaluating resistance of the best fit factor structure to gender differences in the manifestation of anxiety, consistently presented in the literature 31 , and construct validity within a community sample. More specifically, our objectives were: (i) examine the factor structure of the GAD-7 comparing the one-dimensional model with the two-factor model (somatic and cognitive-emotional latent factors); (ii) test the measurement invariance of the factor 
structure of GAD-7 across gender; (iii) explore the construct validity (mainly convergent validity) of the tool associating it with other measures that assess constructs, such as anxiety, depression and consumption behaviors.

\section{Materials and methods}

\section{Participants and procedures}

This validation study with data collected cross-sectionally was approved by the Polytechnic Institute of Coimbra, Coimbra, Portugal, and data came from a web-based survey of college students' mental health and health risk behaviors. The link to the survey was distributed in the six schools of the Institute through external relations offices, on-line newspapers and students' mailing lists. Seven point one percent of the students were surveyed in person at the psychology offices of the Social Services of the Polytechnic Institute of Coimbra and Higher Engineering Institute of Coimbra. The research objectives, procedures, benefits and risks were presented on the first page of the survey, emphasizing the voluntary and anonymous character of the research. Informed consent was signed by all participants and in on-line surveys "I agree" or "I do not agree" buttons replaced signatures. The final sample was composed of 1,031 Portuguese college students. The inclusion criteria were: (i) attending a college course and (ii) being 18 years or more. Self-report measures were administered through a single online access.

\section{Measures}

- Sociodemographic questionnaire: the sociodemographic questionnaire includes items about educational status (study cycle, training area, etc.) and medical and psychiatric history (medication, previous psychological counselling, etc.).

- GAD-7: the GAD-7 is a seven-item scale that assesses general anxiety symptoms mentioned in the DSM-IV (Diagnostic and Statistical Manual of Mental Disorders, 4th edition). In this self-report measure, participants were asked to rate their anxiety-related problems during the two weeks prior to administration of the questionnaire on a 4-point scale $(0=$ not at all, to $3=$ nearly every day). The total scores range from 0 to 21 and higher scores in GAD-7 were associated with more severe generalized anxiety. Regarding severity categories, we followed the recommendations of the original authors 11: none/ normal ( 0 to 5 points), mild ( 5 to 9 points), moderate (10 to 14 points) and severe (15 to 21 points). The psychometric properties of the GAD-7 Portuguese version ${ }^{19}$ were studied using a psychiatric sample with diagnosis of generalized anxiety disorder according to DSM-IV-TR criteria 28 . The GAD-7 presented a one-dimensional structure and good internal consistency $(\alpha=0.88)$.

- HADS: the HADS was used to assess college students' anxiety and depression 12 as a convergent measure of GAD-7. This self-report questionnaire is composed of two subscales with seven items assessing anxiety (HADS-A) and depression (HADS-D). Participants are asked to give their answers according to a 4-point scale (0-3). Each subscale is scored separately and the severity of symptoms follows the following classification: normal (0 to 7 points), mild (8 to 10 points), moderate (11 to 14 points) and severe (15 to 21 points). The HADS has shown good psychometric properties in clinical and non-clinical settings 32,33 , and the Portuguese version ${ }^{34}$ presented good internal consistency with alpha values ranging from 0.76 and 0.81 . In the present study, Cronbach's alpha values were 0.84 for HADSA and 0.80 for HADS-D.

- University Student Risk Behaviors Questionnaire: by Santos 35, this self-report measure was used to test the sensitivity of GAD-7 to consumption behaviors. The University Student Risk Behaviors Questionnaire is composed of 24 items assessing risk behaviors of university students within six categories (1) tobacco use; (2) consumption of alcohol and other drugs; (3) sexual behaviors; (4) eating habits; (5) physical inactivity; (6) risk driving behavior. Participants are asked to answer it using a 5-point scale (1-5) but each item is individually analyzed. Considering the objectives of this study, only nine questions associated with the frequency of the consumption behaviors in the last 30 days were considered in our analysis (for example, "During the past 30 days, on how many days did you smoke cigarettes?"). 


\section{Statistical methods}

The factor structure of GAD-7 was explored through CFA using MPlus, version 6.12 (Muthén \& Muthén, Los Angeles, USA). The two models were tested (one-factor model vs two-factor model) Using weighted least squares with mean and variance adjustment (WLSMV) given the categorical nature of the measure 36. More specifically, the two-factor model included as latent factors, a cognitive-emotional factor composed of items 1, 2, 3 and 7, and a somatic factor integrating items 4, 5 and 6. The chi-square test $\left(\chi^{2}\right)$ is recommended to assess the magnitude of the discrepancy between hypothesized and observed models 37 . A non-significant $\chi^{2}$ is expected for a good model fit 38. However, considering the sensitivity of the $\chi^{2}$ statistic to large samples 39 , we also evaluated other fit indexes recommended by $\mathrm{Hu} \&$ Bentler 37: (i) the comparative fit index (CFI), which compares the sample covariance matrix with an independence model (all indicators' variables were zero) and (ii) root-mean-square error of approximation (RMSEA), which demonstrates how the parameters estimation would fit the population covariance matrix. The weighted root mean square residual (WRMR) generated by MPlus was also included to measure the weighted difference between sampling covariance and population covariance. Thus, the criteria for a good model fit were CFI $\geq 0.95$, RMSEA $<0.0636$ and WRMR < 1.040 . Considering that none of the proposed models had a fair fit, MPlus derived modification statistics were examined. A modified one-factor model, which was not initially hypothesized, allowing the error of items 4 and 5 , and 5 and 6 to covary was also tested to check if it would improve the fit.

In addition, the multiple-group analysis was also conducted to assess the invariance of the best-fit model across male and female groups. The configural and metric invariance was explored based on the definitions proposed by Dimitrov 41. First, we established the same pattern of factors and loadings across gender. The model was run with factor loadings and item thresholds freely estimated in both groups, the scale factor fixed to 1 and mean fixed to zero. This unconstrained model was compared with an equally constrained model using the DIFFTEST chi-square procedure in MPlus.

Finally, to examine the convergent validity between GAD-7 and HADS measures, the IBM SPSS version 24 (IBM Corp., Armonk, USA) was used. Pearson correlation coefficient and analysis of variance were performed considering GAD-7 as a continuous and categorical variable, respectively. The distribution within the severity bands of the two questionnaires was also examined with $\chi^{2}$. Spearman's rank correlation coefficient was used to test the association between GAD-7 and consumption behaviors.

\section{Results}

\section{Participant characteristics}

The final sample included 1,031 college students: 739 females and 292 males. Most students were single $(87.3 \%)$ and more than $50 \%$ were attending health $(32.1 \%)$ or social science $(26.2 \%)$ courses. Among college students, $74.4 \%$ were studying towards a first degree, $16.6 \%$ a master degree and $8.7 \%$ a PhD. Fifty nine point two percent of the students were living away from home. Regarding clinical variables, $14.8 \%$ of participants were taking regular medication for chronic diseases (for example, hypo/hyperthyroidism, asthma and diabetes) or for other medical conditions and $7.1 \%$ had received psychological counselling. In our sample, considering the GAD-7 cut-off criteria, 32.8\% of students had significant generalized anxiety symptoms (scores $\geq 8$ ) 30. More specifically, regarding the GAD-7 score $11,36.3 \%$ of the total sample reported mild anxiety symptoms, $15.6 \%$ moderate symptoms and $8.3 \%$ severe symptoms.

\section{Comparing GAD-7 one-factor and two-factor models}

CFA was performed to evaluate the one and two-factor models. The original single-factor model included all seven items loading onto single generalized anxiety. The two-factor model integrated four cognitive-emotional items and three somatic items. The $\chi^{2}$ value was significant for both models $(\mathrm{p}<0.001)$ as shown in Table 1 . This value is sensitive to sample size, indicating significant misfit even in good fit models 42 . Therefore, other fit indexes were considered, providing a marginal fit 
Table 1

Summary of Generalized Anxiety Disorder 7-item (GAD-7) factor models ( $N=1,031)$.

\begin{tabular}{|c|c|c|c|c|c|c|c|}
\hline Model & Item & $\begin{array}{c}\text { Number } \\
\text { of free } \\
\text { parameters }\end{array}$ & $\chi^{2}$ & df & CFI & RMSEA $(90 \% \mathrm{CI})$ & WRMR \\
\hline One-factor & All items on generalized anxiety factor & 28 & 114.01 * & 14 & 0.994 & $0.083(0.069-0.090)$ & 1.035 \\
\hline Two-factor & $\begin{array}{l}\text { Cognitive-emotional: 1, 2, } 3 \text { and } 7 \\
\text { Somatic tension: 4, } 5 \text { and } 6\end{array}$ & 29 & 84.54 * & 13 & 0.995 & $0.073(0.059-0.088)$ & 0.879 \\
\hline $\begin{array}{l}\text { Modified one-factor } \\
\text { model }\end{array}$ & $\begin{array}{l}\text { A model allowing the error terms of } \\
\text { items } 4 \text { and } 5 \text {, and } 5 \text { and } 6 \text { to covary }\end{array}$ & 30 & 59.07 * & 12 & 0.997 & $0.062(0.047-0.078]$ & 0.724 \\
\hline
\end{tabular}

CFI: comparative fit index; df: degrees of freedom; RMSEA: root-mean-square error of approximation; $\chi^{2}$ : chi-square test; WRMR: weighted root mean square residual.

* $p<0.001$.

of the original model. The cut-off criteria of CFI $\geq 0.95$ was fulfilled but RMSEA was higher than 0.06 and WRMR was higher than 1. Comparing the two factorial structures, the one-factor model was more parsimonious, presenting a lower number of parameters. The multidimensional structure presented a relatively better RMSEA index, but the value remained above 0.06 . Regarding the WRMR index, data confirmed that the weighted mean difference between sampling and population covariance was lower for the two-factor model, being within the cut-off criterion (WRMR $<1$ ). All standardized factor loadings for the two-factor model were significant $(\mathrm{p}<0.001)$ and ranged from 0.592 to 0.752 for the cognitive-emotional latent factor and from 0.717 to 0.831 for the somatic factor. The variance residual was close to zero. Both factors presented good internal consistency (Cronbach's alpha values of 0.85 and 0.86 for cognitive-emotional and somatic factors, respectively). Despite this, data reported an excessively high correlation between the two latent factors $(r=0.961 ; p<0.001)$ indicating that their constructs may be better modeled as a single construct 43 . Based on examination of the modification indices, a modified one-dimensional model allowing the residual variance for items 4 and 5 , and 5 and 6 was examined. A similar model was proposed by Kertz et al. 21, but here the error terms 4 and 6 did not covary. This modified model showed an improved fit relative to the baseline model (Table 1). More specifically, RMSEA was 0.062 , indicating that the model parameters more closely replicated the population covariance compared to the first two models tested. Following the recommendations of MacCallum et al. 44, this value can be accepted as an indicator of a fair fit. Additionally, CFI and WRMR indexes confirmed a well-fitting model. The factor loadings of the modified single-factor model are shown in Figure 1.

Testing GAD-7 factor invariance across gender: a multiple-group CFA

To examine the invariance of the modified one-factor model across gender, a multiple-group CFA was performed (Table 2). The fit model with both groups was estimated, suggesting an acceptable fit based on CFI and RMSEA indexes (CFI = 0.996; RMSEA =0.052; 90\%CI: 0.039-0.065). A DIFFTEST procedure was used to test the metric factorial invariance model. Significant differences were found between men and women $\left(\chi^{2}{ }_{(4)}=43.074 ;<0.001\right)$. However, due to this large sample size, the chi-square test can be misleading. So, $\triangle$ CFI (CFI constrained - CFI unconstrained) was examined, being more appropriate for large samples 45 . The $\Delta$ CFI was -0.002 confirming the invariance between genders.

\section{Construct validity of the GAD-7}

Scores on the GAD-7 were strongly associated with scores on the HADS for the total sample. Results showed that HADS-A $(\mathrm{r}=0.76 ; \mathrm{p}<0.001)$ and HADS-D $(\mathrm{p}<0.54 ; \mathrm{p}<0.001)$ were positively correlated 
Figure 1

Modified one-factor model: the best fitting model.

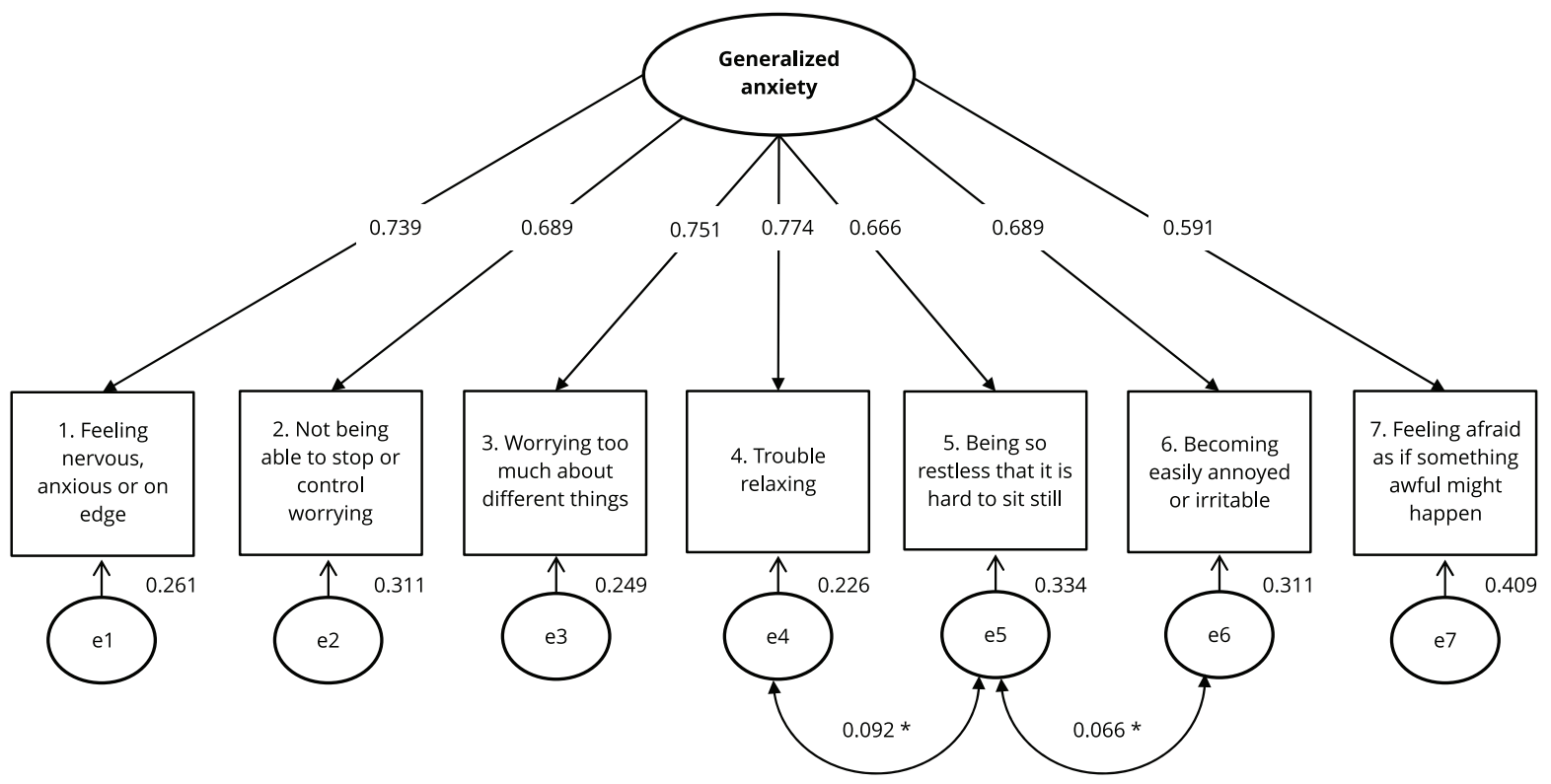

$* \mathrm{p}<0.001$.

Note: standardized estimates based on confirmatory factor analysis (CFA). All factor loadings were significant statistics $(p<0.001)$.

Table 2

Summary of multiple-group confirmatory factor analysis (CFA): standardized coefficients.

\begin{tabular}{|c|c|c|c|c|}
\hline & \multicolumn{2}{|c|}{ Male $(n=292)$} & \multicolumn{2}{|c|}{ Female $(n=739)$} \\
\hline & Factor loading & Residual variance & Factor loading & Residual variance \\
\hline 1. Feeling nervous, anxious or on edge & 0.820 & 0.180 & 0.691 & 0.249 \\
\hline 2. Not being able to stop or control worrying & 0.768 & 0.232 & 0.649 & 0.282 \\
\hline 3. Worrying too much about different things & 0.740 & 0.260 & 0.763 & 0.156 \\
\hline 4. Trouble relaxing & 0.723 & 0.277 & 0.795 & 0.126 \\
\hline 5. Being so restless that it is hard to sit still & 0.679 & 0.321 & 0.662 & 0.235 \\
\hline 6. Becoming easily annoyed or irritable & 0.724 & 0.276 & 0.665 & 0.247 \\
\hline 7. Feeling afraid as if something awful might happen & 0.700 & 0.300 & 0.542 & 0.400 \\
\hline
\end{tabular}

with GAD-7. Considering differences across the GAD-7 severity groups after controlling the effect of age and gender, we confirmed that participants with increasing generalized anxiety symptoms tended to report higher HADS-A and HADS-D scores $(\mathrm{p}<0.001$; Table 3$)$. This data suggested that this scale assesses anxiety status and can be sensitive to depressive symptoms among students. Regarding distribution within cut-off bands in GAD-7 and HADS-A, significant differences were found $\left(\chi^{2}=603.36\right.$; $\mathrm{p}<0.001$ ), but the classification in this measure was not completely independent. College students with scores in the "normal" band (scores < 8) in HADS-A also reported normal or mild anxiety symptoms in GAD-7 ( $\mathrm{M}=4.20$; $\mathrm{SD}=3.41)$. As shown in Table 4, significant correlations were found 
Table 3

Relationship between Generalized Anxiety Disorder 7-item (GAD-7) score and Hospital Anxiety and Depression Scale (HADS).

\begin{tabular}{|c|c|c|}
\hline \multirow[t]{2}{*}{ Level of generalized anxiety symptoms } & HADS-A & HADS-D \\
\hline & Mean $(95 \% \mathrm{Cl})$ & Mena $(95 \% \mathrm{Cl})$ \\
\hline Normal (0-4) & $3.27(3.01-3.53)$ & $2.40(2.11-2.70)$ \\
\hline Mild (5-9) & $6.78(6.51-7.04)$ & 4.88 (4.57-5.19) \\
\hline Moderate (10-14) & $9.29(8.88-9.70)$ & $6.47(6.00-6.94)$ \\
\hline Severe (15-21) & $12.18(11.62-12.74)$ & 8.44 (7.79-9.09) \\
\hline
\end{tabular}

95\% Cl: 95\% confidence intervals; HADS-A: subscales of HADS with seven items assessing anxiety; HADS-D: subscales of HADS with seven items assessing depression.

Note: all pairwise comparison of mean scores between each GAD-7 level within each measurement are significant at $p<0.001$

using Bonferroni correction.

Table 4

Relationship between Generalized Anxiety Disorder 7-item (GAD-7) score and tobacco, alcohol and other drugs use.

\begin{tabular}{|c|c|c|c|c|c|c|c|c|c|c|}
\hline Consumption behavior & 1 & 2 & 3 & 4 & 5 & 6 & 7 & 8 & 9 & 10 \\
\hline 1. GAD-7 total score & - & & & & & & & & & \\
\hline 2. Tobacco use & 0.064 * & - & & & & & & & & \\
\hline 3. Tobacco use (cigarettes per day) & 0.055 & $0.975 * \star$ & - & & & & & & & \\
\hline $\begin{array}{l}\text { 4. Consumption of at least one } \\
\text { alcoholic beverage }\end{array}$ & -0.064 * & $0.378 * \star$ & $0.376 * \star$ & - & & & & & & \\
\hline $\begin{array}{l}\text { 5. Consumption of } 5 \text { or } 4 \text { (women) } \\
\text { alcoholic beverages consecutively }\end{array}$ & -0.013 & $0.368 * \star$ & 0.372 ** & $0.662 * \star$ & - & & & & & \\
\hline $\begin{array}{l}\text { 6. Alcohol consumption in academic } \\
\text { parties (glasses) }\end{array}$ & -0.088 & $0.364 * \star$ & $0.361 * \star$ & $0.567 * *$ & $0.597 * *$ & - & & & & \\
\hline 7. Marijuana use & -0.026 & 0.332 ** & $0.326 * *$ & $0.233 * *$ & $0.279 * *$ & $0.296 * \star$ & - & & & \\
\hline 8. Cocaine use & -0.022 & $0.141 * \star$ & $0.142 * *$ & 0.077 * & $0.141 \star \star$ & $0.099 * \star$ & $0.300 * \star$ & - & & \\
\hline $\begin{array}{l}\text { 9. Consumption of tranquilizers } \\
\text { or barbiturates (without medical } \\
\text { consent) }\end{array}$ & $0.199 * *$ & 0.021 & 0.021 & -0.039 & -0.038 & -0.042 & 0.033 & $0.120 * *$ & - & \\
\hline 10. Synthetic drugs use & -0.014 & $0.146 * \star$ & $0.157 * \star$ & $0.106 * \star$ & 0.156 ** & $0.145 * *$ & $0.364 * *$ & $0.569 * \star$ & $0.120 * \star$ & - \\
\hline
\end{tabular}

* $\mathrm{p}<0.05$

** $\mathrm{p}<0.001$

Note: Spearman's rank correlation coefficient.

between tobacco use and consumption of at least one alcoholic beverage and GAD-7 total score. However, only the positive association between GAD-7 scores and consumption of tranquilizers or barbiturates (without medical consent) had a greater effect size although still small $(\mathrm{r}=0.199 ; \mathrm{p}<0.001)$.

\section{Discussion}

To our knowledge, this is the first study to provide comprehensive validation of the GAD-7 using a sample of college students. Responding to our main aim, we confirmed the measurement model of the GAD-7 scale showing that a multidimensional structure did not fit the data well. This tool also reported good convergent validity with other measures that assess related constructs, such as global anxiety and depression, but low sensitivity to consumption behaviors. 
More specifically, regarding the factorial structure of the measure, our findings proposed a modified one-factor model as an acceptable solution. The original factorial model presented an overall marginal fit, but its respecification considering the dependency of items 4 ("trouble relaxing") and 5 ("being so restless that it is hard to sit still"), and 6 ("becoming easily annoyed or irritable") showed a better fit with the population covariance matrix. Although these items obviously share residual variance over and above what is accounted for by the main latent construct, a two-factor model including autonomic/physical and cognitive nature of the symptoms as independent factors was not appropriate within the academic setting, considering our representative sample.

First, contrary to the model tested by Kertz et al. 21, items 4 and 6 are of a somatic nature but their error terms did not covary. Secondly, the correlation close to unit between factors included in the two-factor structure (3 somatic items and 4 cognitive-emotional items) indicated that they could not be easily differentiated. A multidimensional structure of the GAD-7 may be appropriate for heterogeneous psychiatric samples, as shown by Beard \& Björgvinsson 20, but not for non-clinical samples. However, the clinical judgement of the health professional should consider the somatic and cognitiveemotional nature of generalized anxiety disorder symptoms, minimizing the confusion with other anxiety diagnoses that, as shown by Ruscio et al. 29 , have overlapping symptoms. Additionally, the proposed modified single factor model resisted gender differences and it is therefore generalizable. Configural invariance was confirmed and multiple-group CFA using DIFFTEST supported the assumption of metric invariance across men and women.

When we examined the convergence between GAD-7 and HADS-A and HADS-D measures, the results showed a monotonic increase in HADS-A and in HADS-D scores with increasing GAD-7 scores. This finding indicated the sensitivity of the generalized anxiety disorder tool to anxiety status but also to depressive symptoms, although with a smaller effect size, showing some discriminant validity of the measure. The relationship with depression is not surprising since GAD has been reported as a predictor of mood disorders 29 , which can later coexist 46 . Comparing the severity bands of GAD-7 with HADS-A bands, just like the recent conclusions by Sousa et al.19, the classification in this measure was not completely independent. However, distribution differences confirmed in our analysis point to GAD-7 as an equally valid measure to assess anxiety symptoms, but more specifically, to assess symptoms of generalized anxiety disorder.

Furthermore, the association found between GAD-7 scores and consumption of tranquilizers or barbiturates (without medical consent) was also an indicator of the tool's construct validity. Despite the small effect size of this association, our data may indicate the sensitivity of the tool to this specific type of consumption. Moreover, some university students can try to minimize generalized anxiety disorder symptoms through self-medication. Thus, this relationship should be explored in future studies of this construct and, more rigorously, the predictive validity of this measure for this specific consumption. Nonetheless, the associations between generalized anxiety disorder and alcohol and substance use present in the findings of Conway et al. ${ }^{9}$ and Grant et al. ${ }^{10}$ have not been shown, confirming the low sensitivity of the measure to these consumption behaviors in our college student sample.

To summarize, our study proposes the Portuguese version of GAD-7 as a short and valid tool for evaluation of generalized anxiety disorder in university students, replacing more general measures. Despite this, some limitations should also be considered when interpreting the results. First, to confirm the factorial model of GAD-7, only college student samples collected in Portugal were used. Secondly, data collection was predominantly web-based, increasing participation bias 47 . Therefore, it should not be concluded that this model is applicable to all college students within other cultures/ languages. Additionally, a clinical interview may be used in future studies to explore the sensitivity and specificity of the GAD-7 in the academic setting. The inclusion of functional measures for a more robust test of the tool's construct validity could also be explored in future researches and, particularly, the association between domains of quality of life and generalized anxiety disorder, which is well established 48. Finally, we recommend that the multidimensional structure of GAD-7 should be examined in other clinical and non-clinical conditions using CFA procedures, since most studies fail in this analysis. 


\section{Contributors}

A. Bártolo participated in the project conception, analysis and interpretation of data and writing of the manuscript. S. Monteiro contributed in the project conception, analysis and interpretation of results and critical review. A. Pereira participated in the project design, analysis and interpretation of results and critical review.

\section{References}

1. Auerbach RP, Alonso J, Axinn WG, Cuijpers P, Ebert DD, Green JG, et al. Mental disorders among college students in the World Health Organization World Mental Health Surveys. Psychol Med 2016; 46:2955-70.

2. Fortney JC, Curran GM, Hunt JB, Cheney AM, $\mathrm{Lu} \mathrm{L}$, Valenstein M, et al. Prevalence of probable mental disorders and help-seeking behaviors among veteran and non-veteran community college students. Gen Hosp Psychiatry 2016; 38:99-104.

3. Boehm MA, Lei QM, Lloyd RM, Prichard JR. Depression, anxiety, and tobacco use: overlapping impediments to sleep in a national sample of college students. J Am Coll Health 2016; 64:565-74.

4. Vitasari P, Wahab MNA, Othman A, Herawan T, Sinnadurai SK. The relationship between study anxiety and academic performance among engineering students. In: Tarmizi RA, Ayub AFM, editors. Procedia: social and behavioral sciences. Malacca: Elsevier Procedia; 2010. p. 490-7.

5. Eisenberg D, Hunt J, Speer N. Mental health in American colleges and universities: variation across student subgroups and across campuses. J Nerv Ment Dis 2013; 201:60-7.

6. Somers JM, Goldner EM, Waraich P, Hsu L. Prevalence and incidence studies of anxiety disorders: a systematic review of the literature. Can J Psychiatry 2006; 51:100-13.

7. Yonkers KA, Warshaw MG, Massion AO, Keller MB. Phenomenology and course of generalised anxiety disorder. Br J Psychiatry 1996; 168:308-13

8. Barrera TL, Norton PJ. Quality of life impairment in generalized anxiety disorder, social phobia and panic disorder. J Anxiety Disord 2009; 23:1086-90.

9. Conway KP, Compton W, Stinson FS, Grant BF. Lifetime comorbidity of DSM-IV mood and anxiety disorders and specific drug use disorders: results from the National Epidemiologic Survey on Alcohol and Related Conditions. J Clin Psychiatry 2006; 67:247-57.

10. Grant BF, Stinson FS, Dawson DA, Chou SP, Dufour MC, Compton W, et al. Prevalence and co-occurrence of substance use disorders and independent mood and anxiety disorders: results from the National Epidemiologic Survey on Alcohol and Related Conditions. Arch Gen Psychiatry 2004; 61:807-16.

11. Spitzer RL, Kroenke K, Williams JB, Löwe B. Anxiety disorders in primary care: prevalence, impairment, comorbidity, and detection. Arch Intern Med 2006; 166:1092-7. 
12. Zigmond AS, Snaith RP. The Hospital Anxiety and Depression Scale. Acta Psychiatr Scand 1983; 67:361-70.

13. Spielberger CD, Gorssuch RL, Lushene PR, Vagg PR, Jacobs GA. Manual for the state-trait anxiety inventory. Palo Alto: Consulting Psychologists Press; 1983.

14. Donker T, van Straten A, Marks I, Cuijpers P. Quick and easy self-rating of generalized anxiety disorder: validity of the Dutch web-based GAD-7, GAD-2 and GAD-SI. Psychiatry Res 2011; 188:58-64.

15. García-Campayo J, Zamorano E, Ruiz M, Pardo A, Pérez-Páramo M, López-Gómez V, et al. Cultural adaptation into Spanish of the Generalized Anxiety Disorder-7 (GAD-7) scale as a screening tool. Health Qual Life Outcomes 2010; 8:8.

16. Mills SD, Fox RS, Malcarne VL, Roesch SC, Champagne BR, Sadler GR. The psychometric properties of the generalized anxiety disorder-7 scale in Hispanic Americans with English or Spanish language preference. Cultur Divers Ethnic Minor Psychol 2014; 20:463-8.

17. Moreno AL, DeSousa DA, Souza AMFLP, Manfro GG, Salum GA, Koller SH, et al. Factor structure, reliability, and item parametersof the Brazilian-Portuguese version of the GAD-7 questionnaire. Trends Psychol 2016; 24:367-76.

18. Rogers KD, Young A, Lovell K, Campbell M, Scott P, Kendal S. The British sign language versions of the Patient Health Questionnaire, the Generalized Anxiety Disorder 7-Item Scale, and the Work and Social Adjustment Scale. J Deaf Stud Deaf Educ 2012; 18:110-22.

19. Sousa TV, Viveiros V, Chai MV, Vicente FL, Jesus G, Carnot MJ, et al. Reliability and validity of the Portuguese version of the Generalized Anxiety Disorder (GAD-7) Scale. Health Qual Life Outcomes 2015; 13:50.

20. Beard C, Björgvinsson T. Beyond generalized anxiety disorder: psychometric properties of the GAD-7 in a heterogeneous psychiatric sample. J Anxiety Disord 2014; 28:547-52.

21. Kertz SJ, Bigda-Peyton J, Björgvinsson T. Validity of the GAD-7 in an acute psychiatric setting. Clin Psychol Psychother 2013; 20:456-64.
22. Barthel D, Barkmann C, Ehrhardt S, Bindt C. Psychometric properties of the 7-item Generalized Anxiety Disorder Scale in antepartum women from Ghana and Côte d'Ivoire. J Affect Disord 2014; 169:203-11.

23. Micolaud-Franchi J-A, Lagarde S, Barkate G, Dufournet B, Besancon C, Trébuchon-Da Fonseca A, et al. Rapid detection of generalized anxiety disorder and major depression in epilepsy: validation of the GAD-7 as a complementary tool to the NDDI-E in a French sample. Epilepsy Behav 2016; 57:211-6.

24. Terrill AL, Hartoonian N, Beier M, Salem R, Alschuler $\mathrm{K}$. The 7-item generalized anxiety disorder scale as a tool for measuring generalized anxiety in multiple sclerosis. Int J MS Care 2015; 17:49-56.

25. Zhong Q-Y, Gelaye B, Zaslavsky AM, Fann JR, Rondon MB, Sánchez SE, et al. Diagnostic validity of the Generalized Anxiety Disorder-7 (GAD-7) among pregnant women. PLoS One 2015; 10:e0125096.

26. Löwe B, Decker O, Müller S, Brähler E, Schellberg D, Herzog W, et al. Validation and standardization of the generalized anxiety disorder screener (GAD-7) in the general population. Med Care 2008; 46:266-74.

27. Wild B, Eckl A, Herzog W, Lechner S, Maatouk I, Schellberg D, et al. Assessing generalized anxiety disorder in elderly people using the GAD-7 and GAD-2 scales: results of a validation study. Am J Geriatr Psychiatry 2014; 22:1029-38

28. American Psychiatric Association. Diagnostic and statistical manual of mental disorders (DSM-IV-TR). Lisbon: Climepsi Editores; 2002.

29. Ruscio AM, Chiu WT, Roy-Byrne P, Stang PE, Stein DJ, Wittchen HU, et al. Broadening the definition of generalized anxiety disorder: effects on prevalence and associations with other disorders in the national comorbidity survey replication. J Anxiety Disord 2007; 21:662-76.

30. Kroenke K, Spitzer RL, Williams JB, Monahan PO, Löwe B. Anxiety disorders in primary care: prevalence, impairment, comorbidity, and detection. Ann Intern Med 2007 46:317-25. 
31. McLean CP, Asnaani A, Litz BT, Hofmann SG. Gender differences in anxiety disorders: prevalence, course of illness, comorbidity and burden of illness. J Psychiatr Res 2011; 45:1027-35.

32. Bjelland I, Dahl AA, Haug TT, Neckelmann, D. The validity of the Hospital Anxiety and Depression Scale: an updated literature review. J Psychosom Res 2002; 52:69-77.

33. Snaith RP. The Hospital Anxiety And Depression Scale. Health Qual Life Outcomes 2003; 1:29.

34. Pais-Ribeiro J, Silva I, Ferreira T, Martins A, Meneses R, Baltar M. Validation study of a Portuguese version of the Hospital Anxiety and Depression Scale. Psychol Health Med 2007; 12:225-37.

35. Santos L. Saúde mental e comportamentos de risco em estudantes universitários [Doctoral Disseration]. Aveiro: Universidade de Aveiro; 2011.

36. DiStefano C, Morgan GB. A comparison of diagonal weighted least squares robust estimation techniques for ordinal data. Struct Equ Modeling 2014; 21:425-38.

37. Hu LT, Bentler PM. Cutoff criteria for fit indexes in covariance structure analysis: conventional criteria versus new alternatives. Struct Equ Modeling 1999; 6:1-55.

38. Barrett P. Structural equation modelling: adjudging model fit. Pers Individ Dif 2007; 42:815-24.

39. Jöreskog K. Sörbom D. LISREL 8: structural equation modeling with the SIMPLIS command language. Chicago: Scientific Software International Inc.; 1993.

40. Schreiber JB, Nora A, Stage FK, Barlow EA King J. Reporting structural equation modeling and confirmatory factor analysis results: a review. J Educ Res 2006; 99:323-38.
41. Dimitrov DM. Testing for factorial invariance in the context of construct validation. Meas Eval Couns Dev 2010; 43:121-49.

42. Muthen BO, Muthen LK. MPlus user's guide. Los Angeles: Muthén \& Muthén; 2001.

43. Bowen NK, Guo S. Structural equation modeling. Oxford: Oxford University Press; 2012.

44. MacCallum RC, Browne MW, Sugawara HM Power analysis and determination of sample size for covariance structure modeling. Psychol Methods 1996; 1:130-49.

45. Meade AW, Johnson EC, Braddy PW. Power and sensitivity of alternative fit indices in tests of measurement invariance. J Appl Psychol 2008; 93:568-92.

46. Schoevers RA, Deeg DJ, van Tilburg W, Beekman AT. Depression and generalized anxiety disorder: co-occurrence and longitudinal patterns in elderly patients. Am J Geriatr Psychiatry $2005 ; 13: 31-9$.

47. Heiervang E, Goodman R. Advantages and limitations of web-based surveys: evidence from a child mental health survey. Soc Psychiatry Psychiatr Epidemiol 2011; 46:69-76.

48. Henning ER, Turk CL, Fresco DM, Heimberg RG. Impairment and quality of life individuals with generalized anxiety disorder. Depress Anxiety 2007; 24:342-9. 


\section{Resumo}

A escala Generalized Anxiety Disorder 7-item (GAD-7) tem sido apresentada como medida confiável e válida para avaliar os sintomas da ansiedade generalizada em diversos contextos clínicos e na população geral. Entretanto, algumas pesquisas deixam de apoiar a estrutura unidimensional original da ferramenta GAD-7. O estudo teve como objetivo principal examinar a estrutura fatorial da GAD-7, comparando o ajuste do modelo com um fator versus dois fatores (três sintomas de natureza somática e quatro sintomas de natureza cognitivo-emocional) em uma amostra de alunos universitários. O estudo de validação, com coleta de dados transversais, incluiu 1.031 universitários portugueses matriculados nas seis escolas do Instituto Politécnico de Coimbra, Coimbra, Portugal. As medidas incluíram a escala GAD-7, Hospital Anxiety and Depression Scale (HADS) e University Student Risk Behaviors Questionnaire. Os procedimentos da análise fatorial confirmatória (AFC) confirmaram que nenhuma das estruturas fatoriais demonstrou bom ajuste. Portanto, uma solução apropriada seria um modelo unifatorial modificado que permitisse a covariância dos termos de erro dos itens associados a dificuldades de relaxamento e irritabilidade. Além disso, essa estrutura fatorial revelou invariância métrica e de configuração entre os sexos. Foi encontrada uma boa validade convergente ao correlacionar a ansiedade global com a depressão. Entretanto, essa medida mostrou fraca associação com comportamentos de consumo. Nossos resultados são relevantes para a prática clínica, uma vez que a abordagem abrangente à escala $G A D-7$ contribui para o conhecimento da história dos sintomas de ansiedade generalizada e seus correlatos no contexto universitário.

Ansiedade; Estudantes; Inquéritos e Questionários

\section{Resumen}

La escala de la Generalized Anxiety Disorder 7-item (GAD-7) se ha presentado como una medida confiable y válida para evaluar los síntomas de ansiedad generalizada en varios contextos clinicos y entre la población en general. Sin embargo, algunas investigaciones no apoyan la estructura original unidimensional de la herramienta GAD-7. Nuestro objetivo principal fue examinar la estructura de factores de GAD-7 comparando el ajuste de modelo de un factor con un modelo de dos factores (tres sintomas de naturaleza somática y cuatro sintomas de naturaleza cognitivo-emocional) en una muestra de estudiantes universitarios. Este estudio de validación con datos recogidos transversalmente incluyó 1.031 estudiantes universitarios portugueses que asisten a cursos en las seis escuelas del Instituto Politécnico de Coimbra, Coimbra, Portugal. Las medidas incluyeron el GAD-7, la Hospital Anxiety and Depression Scale (HADS) y University Student Risk Behaviors Questionnaire. Los procedimientos de análisis factorial confirmatorio (CFA) confirmaron que ninguna de las estructuras de factores era adecuada. Así, un modelo de factor único modificado que permite los términos de error de los elementos asociados con las dificultades de relajación y la irritabilidad a covaria fue una solución adecuada. Adicionalmente, esta estructura de factores reveló la invariancia configural y métrica a través del género. Se encontró una buena validez convergente al correlacionar la ansiedad y la depresión globales. Sin embargo, esta medida mostró una asociación débil con los comportamientos de consumo. Nuestros resultados son relevantes para la práctica clínica, ya que el enfoque integral de $G A D-7$ contribuye a conocer la trayectoria de sintomas ansiedad generalizada y sus correlatos en el ámbito universitario.

Ansiedad; Estudiantes; Encuestas y Cuestionarios
Submitted on 15/Dec/2016

Final version resubmitted on 13/Jun/2017

Approved on 27/Jun/2017 